https://www.journal-imab-bg.org

Original article

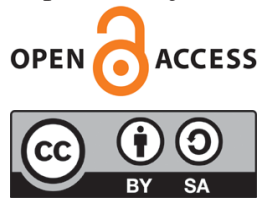

\title{
ANTIBIOTIC SUSCEPTIBILITY/RESISTANCE AMONG SALMONELLA SPECIES ISOLATED IN NON-HOSPITALISED PATIENTS IN THE CANTON OF SARAJEVO
}

\author{
Mufida Aljicevic ${ }^{1, *}$, Armin Cikotic ${ }^{2}$, Sabaheta Bektas ${ }^{3}$, Sabina Mahmutovic \\ Vranic $^{1}$, Velma Rebic ${ }^{1}$, Amila Abduzaimovic ${ }^{1}$, Adem Cemerlic ${ }^{2}$ \\ 1) Department of Microbiology, Faculty of Medicine, University of Sarajevo, \\ Bosnia and Herzegovina. \\ 2) Faculty of Medicine, University of Sarajevo, Bosnia and Herzegovina. \\ 3) Department of Microbiology, Institute for Public Health of Canton Sarajevo, \\ Bosnia and Herzegovina.
}

\begin{abstract}
:
Background: Salmonellosis, a disease which occurs following the consumption of food contaminated with salmonella, is most frequently present in young children and older immunocompromised individuals. This condition must be treated with antibiotics. The increased degree of morbidity comes in relation to the increased resistance of Sallmonellae species to antibiotics. Resistance has considerably been increased in approximately the last twenty years, thanks mostly to the establishment of diagnoses ex juvantibus, the prescription of therapies without antimicrobial susceptibility/resistance testing, as well as the massive, unjustified usage of antibiotics.

Purpose: The goal of this study was to examine the representation of antibiotic susceptibility/resistance of Salmonella species isolated in non-hospitalised patients.

Materials and methods: In a microbiological laboratory in the Institute for Public Health Canton of Sarajevo (Bosnia and Herzegovina), analysed were samples of stool and urine of non-hospitalised patients with our without developed symptoms of salmonellosis in the period from one year.

Results: Of the total 69 patients infected with salmonella, in 65 (94.2\%) S. enteritidis group D was isolated, in 3 $(4.3 \%)$ S. species group B, and in $1(1.4 \%)$ patient there was a $S$. enteritidis group D and a $S$. species group C. Isolated strains were resistant to Ampicillin in 63 (91.3\%) patients, while to Ciprofloxacin and Bactrim there was no established resistance.

Conclusions: The most commonly isolated bacterial strain was $S$. enteritidis group D. Isolated strains show different susceptibility/resistance to tested antibiotics, and thus the completion of an antimicrobial susceptibility/resistance test is necessary before adding an antibiotic to the patient's treatment.
\end{abstract}

Keywords: Salmonella species, salmonellosis, antimicrobial susceptibility test,

\section{INTRODUCTION:}

The genus Salmonella belongs to the family Enterobacteriaceae. Salmonella are a gram-negative, non-sporing, mainly mobile bacilli thanks to their peritrichous flagella [1]. The production of $\mathrm{H}_{2} \mathrm{~S}$ is characteristic of almost all serotypes of this bacteria. The majority of them posses plasmids of $120 \mathrm{~Kb}$, which participate in its virulence [2,3]. Salmonella possess three antigens. On the basis of O-antigen, as a group antigen, all salmonella are divided into 67 groups. Flagellar or $\mathrm{H}$-antigens are proteins and they may be mono-phasic or bi-phasic. On the basis of these antigens conducted is a classification of salmonella according to serotypes. Capsular or Vi-antigen is a polysaccharide. Only some salmonella possess it, such as S. typhi, S. paratyphi A, $\mathrm{B}$, and C $[2,4]$. Salmonella are bacteria which are most frequently found in the bowels of people and animals. They may survive for a long period of time outside the host organism, in water or on the ground, polluted by human or animal feces [3, 5, 6]. The CDC (Centres for Disease Control and Prevention) in 2011 reported that annually, non-typhus salmonella serotypes cause over 23,000 hospitalizations and over 450 cases of death on the territorial United States [7]. The source of infections are infected animals (poultry, pigs, cattle), their products (eggs, meat, milk) and then patients and permanent carriers. The disease from animals is transferred by consuming contaminated food which is insufficiently thermally processed, but also by contact with the select animal, more specifically its secretions. In inter-human transmission, the basis is consumption of food contaminated with feces of the diseased or permanent carriers. The massive industrial production of food items, presence of dining outside of the home, and the import and export of foods from other countries plays an important role in the appearance of salmonella [8]. Antibiotics are not used in the treatment of simple non-typhus salmonellosis gastroenteritis infections. On the other hand, their implementation is mandatory among serious forms of the disease or for highrisk individuals to prevent the continuation of the invasive disease. Throughout history, treatment of salmonellosis in- 
cluded Ampicillin, Co-trimoxazole, or Chloramphenicol. However, increased resistance to these listed drugs in the near past has led the way for their limited usage. Currently, Fluoroquinolones and third generation Cephalosporins have an advantage for empirical therapy $[9,10]$. Antibiotic therapy lasts 10-14 days. It is important to compensate for the lost fluids and electrolytes peri-orally or parenterally. A chronic carrier represents the presence of salmonella in the stool or urine of an individual longer than one year [8, 11, 12]. Removing the source of infection includes detection, isolation, and treatment of infected animals, detection of their products with the recall from consumer sale and usage and/ or their complete removal/destroying, isolation and treatment of the diseased individual, and the detection and treatment of the carriers. Pathways of disease spreading are food, water, and dirty hands $[13,14]$.

\section{MATERIALS AND METHODS :}

Study population - The research study is a retrospective analytical study. It was conducted in a microbiological laboratory in the Institute for Public Health in the Canton of Sarajevo, Bosnia and Herzegovina. Processed were 159 positive samples from non-hospitalized patients from the territory of Canton Sarajevo cover the period of one year. Samples were stool and urine from patients with developed symptoms of salmonellosis, as well as from patients without those symptoms (taken in the scope of a sanitary examination). The middle of the stream of the first morning urine and stool samples were taken in the appropriate sterile containers.

Methods - After identification of Salmonella species in the stool and urine samples, we further demonstrated for antimicrobial susceptibility testing by Müller-Hinton (MH) agar using Kirby-Bauer disc diffusion method of antibiogram, which is based on the principle of antibiotic diffusion into a nutritive foundation of $\mathrm{MH}$. Used are discs with a precisely regulated concentration of antibiotics: Ampicillin 10mg, Ciprofloxacin 5mg and Bactrim (Trimethoprim + Sulfamethoxazole) $1,25+23,75 \mathrm{mg}$. Antibiotics susceptibility was marked as sensitivity and resistant by using the diameter of zone of inhibition as per the CLSI (Clinical Laboratory Standard Institute) guidelines.

Statistical analysis - The results are shown through tabular and graphic representations of number of cases, percentages, arithmetic means with standard deviation, standard error of arithmetic means and range of values, as well as the median. Statistical analysis was conducted using the Chi-squared test and the Kolmogorov-Smirnov test. The results of all tests are considered significant with the confidence interval of $95 \%$ or with $\mathrm{p}<0,05$. The analysis was conducted using the statistical package IBM Statistics SPSS v23.0.

\section{RESULTS:}

From all analyzed stool and urine samples of nonhospitalised patients, Salmonella was isolated in a total of 159 patients. From that, only 69 patients were with confirmed infections caused by Salmonella species.

On Graph 1 given is the display of distribution of patients with salmonellosis infections according to months, throughout the entire year.

Graph 1. Representation of patients with positive isolated Salmonella species according to months of the year

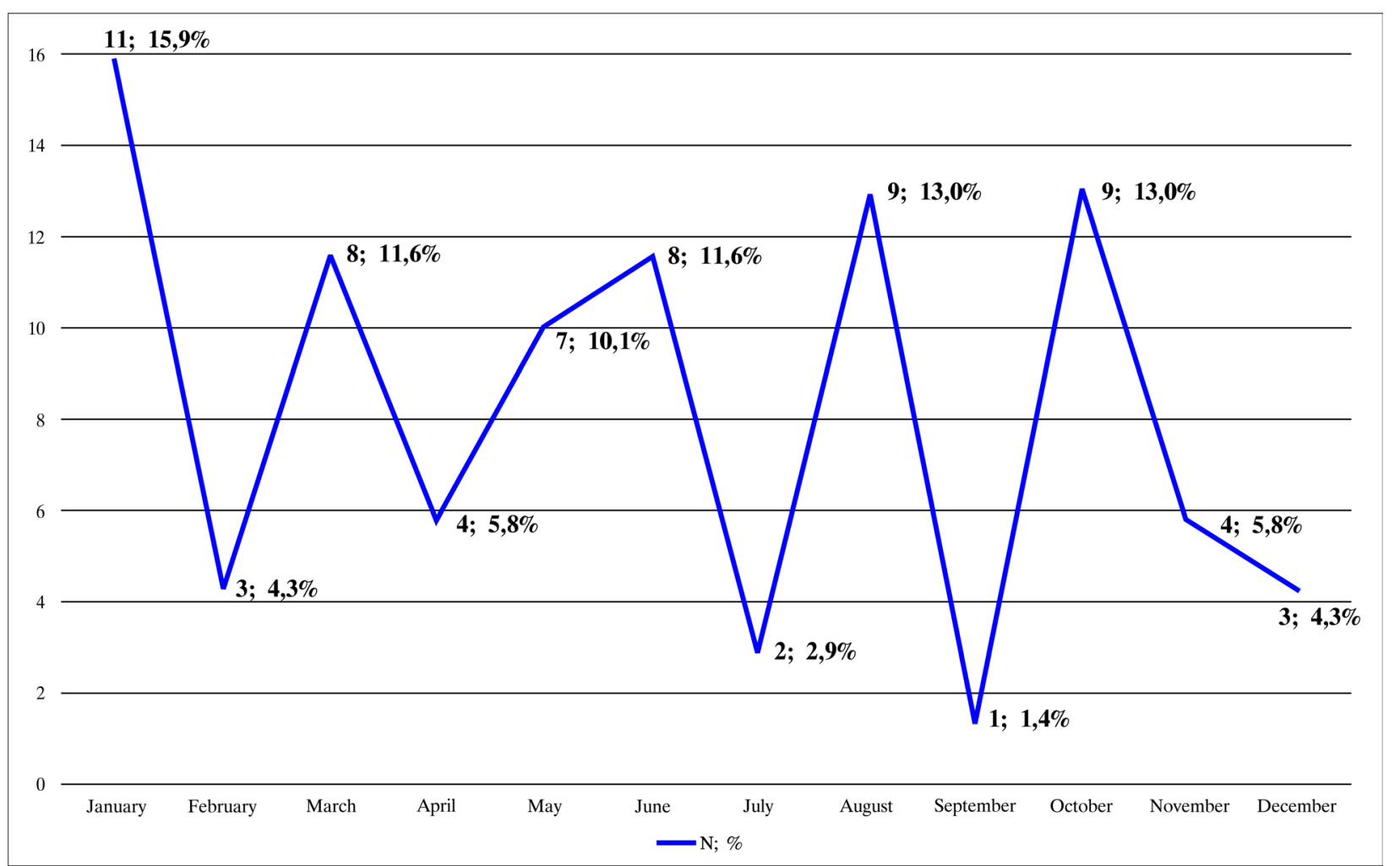


The statistical analysis shows that there is a significant difference in the representation of patients with positive isolated Salmonella species according to months of the year $(\mathrm{p}<0,05)$. In January there was the largest number of patients with positive isolates, a total of 11 (15.95\%). In August and October, this number was a little lower, both months having 9 (13.0\%), and in March and June, 8 each (11.16\%). In May there were $7(10.1 \%)$ patients with positive isolates, while in
April and November there were 4 each (5.8\%). 3 (4.3\%) patients with positive isolates were in February and December, and the least number of patients were in July and September. In July there were $2(2.9 \%)$ and in September only $1(1.4 \%)$.

On Graphs 2 as well as in Tables 1 and 2, given is the display of the results of the examined sensitivity/resistances of isolated salmonella strains to select antibiotics.

Graph 2. Sensitivity/resistance of isolates of Salmonella species to Ampicillin

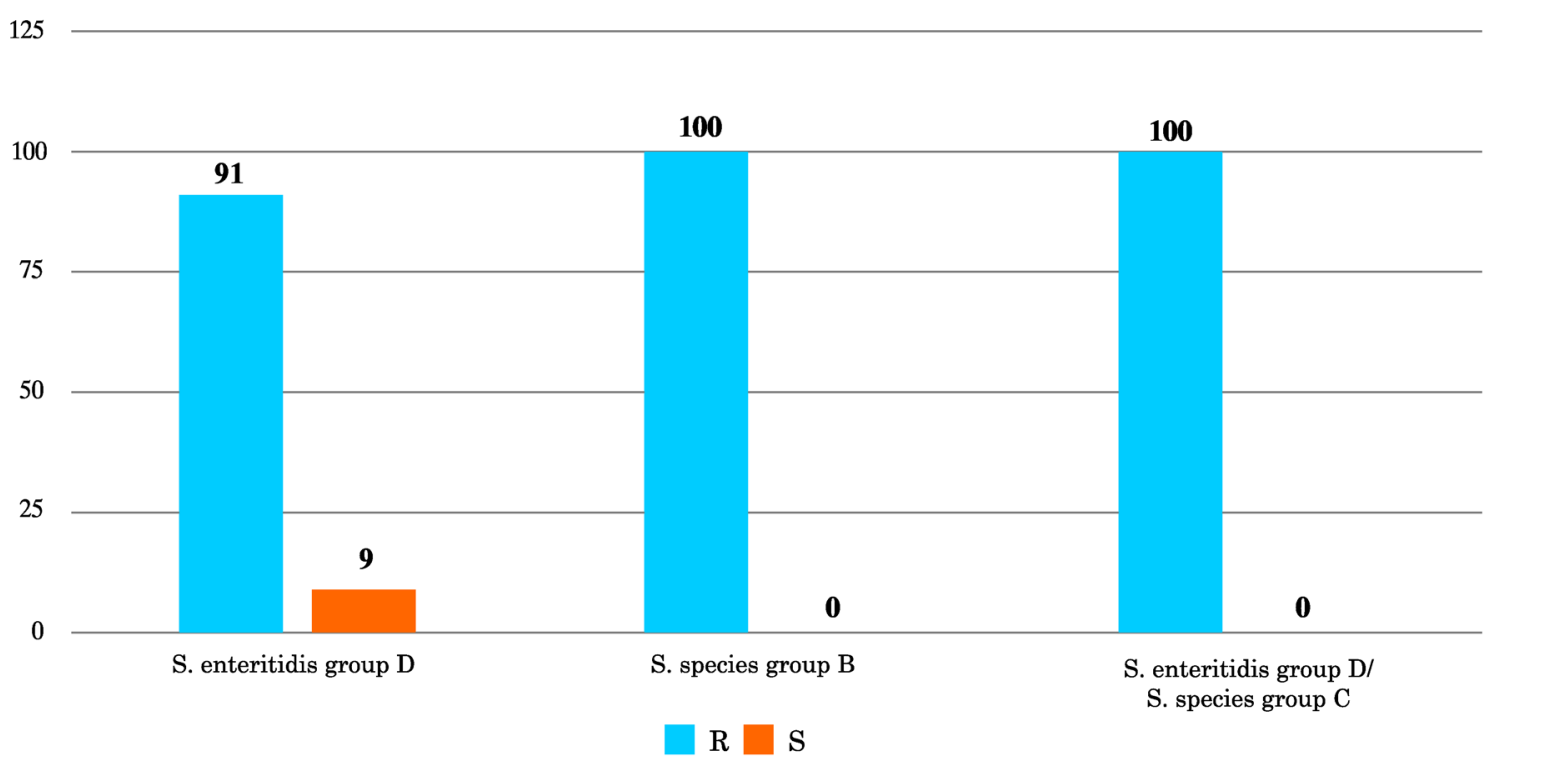

Statistical analysis shows that there exists no significant difference in sensitivity/resistance of isolates of Salmonella species in relation to Ampicillin $(\mathrm{p}>0,05)$. Of 65 patients with isolated S. enteritidis group D, 59 (90.8\%) of them were resistant to Ampicillin, while 6 (9.2\%) were sensitive.

Resistance to Ampicillin is noted even in 3 (100\%) patients with isolated S. species group B and 1 (100\%) patient with isolated $S$. enteritidis group $\mathrm{D} / S$. species group C.

Table 1. Sensitivity of isolates from Salmonella species to Ciprofloxacin

\begin{tabular}{|c|c|c|c|c|}
\hline \multicolumn{5}{|c|}{ Salmonella species $*$ Ciprofloxacin } \\
\hline & & & Ciprofloxacin & Total \\
\hline & & & $\mathbf{S}^{*}$ & \\
\hline \multirow[t]{6}{*}{ Salmonella species } & \multirow[t]{2}{*}{ S. enteritidis group D } & $\mathrm{N}$ & 65 & 65 \\
\hline & & $\%$ & 100,0 & 94,2 \\
\hline & \multirow[t]{2}{*}{ S. species group B } & $\mathrm{N}$ & 3 & 3 \\
\hline & & $\%$ & 100,0 & 4,3 \\
\hline & \multirow{2}{*}{$\begin{array}{l}\text { S. enteritidis group D/ } \\
\text { S. species group C }\end{array}$} & $\mathrm{N}$ & 1 & 1 \\
\hline & & $\%$ & 100,0 & 1,4 \\
\hline \multirow{2}{*}{\multicolumn{2}{|c|}{ Total }} & $\mathrm{N}$ & 69 & 69 \\
\hline & & $\%$ & 100,0 & 100,0 \\
\hline
\end{tabular}

*susceptible (sensitive)

In Table 1 given is the display of isolated serotypes of Salmonella species and the results of examined sensitivity to Ciprofloxacin. Visible clearly are the isolated strains sensitive to Ciprofloxacin in all 69 (100\%) of patients. 
Table 2. Sensitivity of isolates from Salmonella species to Bactrim

\begin{tabular}{|c|c|c|c|c|}
\hline \multicolumn{5}{|c|}{ Salmonella species * Bactrim } \\
\hline & & & \multirow{2}{*}{$\frac{\text { Bactrim }}{\mathbf{S}^{*}}$} & \multirow[t]{2}{*}{ Total } \\
\hline & & & & \\
\hline \multirow[t]{6}{*}{ Salmonella species } & \multirow[t]{2}{*}{ S. enteritidis group D } & $\mathrm{N}$ & 65 & 65 \\
\hline & & $\%$ & 100,0 & 94,2 \\
\hline & \multirow[t]{2}{*}{ S. species group B } & $\mathrm{N}$ & 3 & 3 \\
\hline & & $\%$ & 100,0 & 4,3 \\
\hline & \multirow{2}{*}{$\begin{array}{l}\text { S. enteritidis group D/ } \\
\text { S. species group C }\end{array}$} & $\mathrm{N}$ & 1 & 1 \\
\hline & & $\%$ & 100,0 & 1,4 \\
\hline \multirow{2}{*}{\multicolumn{2}{|c|}{ Total }} & $\mathrm{N}$ & 69 & 69 \\
\hline & & $\%$ & 100,0 & 100,0 \\
\hline
\end{tabular}

*susceptible (sensitive)

In Table 2 given is the display of isolated serotypes of Salmonella species, and the results of examined sensitivity to Bactrim. Visible clearly are the isolated strains sensitive to Bactrim in all $69(100 \%)$ of patients.

\section{DISCUSSION:}

The microbiological laboratory of the Institute for Public Health Canton Sarajevo during the period of 12 months confirmed the infection caused by Salmonella species in 69 non-hospitalised patients with developed symptoms of salmonellosis, but also in those without the characteristic symptomatology. Ampicillin, Ciprofloxacin, and Bactrim are antibiotics upon which sensitivity/resistance of isolated serotypes was examined. The results of the research show that isolated serotypes are resistant to Ampicillin in 63 (91.3\%) patients with salmonellosis infections, while sensitivity shows in only $6(8,7 \%)$ patients. On the other hand, to Ciprofloxacin and Bactrim no resistance of isolated serotypes was established. These results show difference in relation to the results of research conducted in other countries. Differences exist in large percentages of resistance of isolated salmonella serotypes to Ampicillin, as well as in the absence of resistance to the remaining two antibiotics upon which sensitivity/resistance is examined. The committee for following resistance of bacteria to antibiotics in the Republic of Croatia at the Academy of Medical Science Croatia in cooperation with the referral laboratories for following resistance to antibiotics at the Clinic for Infectious Diseases "Dr. F. Mihaljeviæ" regularly follows bacterial resistance to antibiotics in Croatia. In 2014 resistance of salmonella to Ampicillin was listed at $14 \%$ and to Ciprofloxacin $2 \%$, which represents an increase in resistance to the same antibiotic in comparison to 2013, when resistance to Ampicillin was $10 \%$ and to Ciprofloxacin $0 \%$. Resistance to third generation Cephalosporins, in both years, amounted to $0 \%$. Resistance to Co-trimoxazol shows a clear difference, because in 2013 it amounted to $3 \%$ and a year later $2 \%$. In 2015, resistance of salmonella to ampicillin and ciprofloxacin was the largest in the period from 2013 to 2015. To Ampicillin this resistance amounted to $16 \%$ while to Ciprofloxacin $4 \%$. Resistance to Cephalosporins of the third generation and Co-trimoxazol was the same as the previous year. Even in these research studies, the largest resistance to Salmonella species was noted as being to Ampicillin, however in relation to our study it was significantly lower. The largest resistance to Ampicillin in the given period on the territory of Croatia was established in 2015 with a percentage of $16 \%$. Likewise, in all three years of the given time period, resistance to Ciprofloxacin and Co-trikmoxazol (Bactrim) was established, in comparison to our research in which to the listed antibiotics there was no established resistance $[15,16$, 17]. EFSA (European Food Safety Authority) and ECDC (European Centre for Disease Prevention and Control) reported about the resistance of zoonotic bacteria to antibiotics for the 2015 year from a total of 24 European countries (22 members of the European Union, as well as Iceland and Norway). Antibiotic resistance was tested on a total of 15,070 isolates from 281 different salmonella serotypes. Each of the countries mentioned utilised a different number of antibiotics while testing isolates. The largest percentage of resistance to Salmonella species was noted to Sulfamethoxazole (32.4\%), Tetracyclines (28.1\%) and Ampicillin (27.8\%). Resistance to Ciprofloxacin and third generation Cephalosporins, recognised as the most important antibiotics used in treating infections caused by Salmonella species was established at $13.3 \%$ and $0.9 \%$ respectively. These results show the increase in resistance to Ciprofloxacin in comparison to 2014, when the resistance amounted to $8.8 \%$. In 2014 antibiotic resistance was tested upon a total of 14,412 positive isolates from 247 different salmonella serotypes from a total of 22 European countries (21 members of the European Union and Norway). The largest percentage of resistance to Salmonella species was established to Tetracyclines (30.3\%), Sulfamethoxazole (28.6\%) and Ampicillin (28.2\%) [9, 18].

In 2016, the agency for Food Safety Bosnia and Herzegovina published the "Report of the State in the Field of Food Safety in Bosnia and Herzegovina in 2015." In Bosnia and Herzegovina, from the period of 01.01. to 12.31.2015, a total of 34,469 samples of food were sampled and microbiologically processed. Meat and meat products, as well as ice cream (in whose composition are eggs and milk) are food 
from which Salmonella species is most commonly isolated. These results confirm what was mentioned earlier, that milk, eggs, and cheese are the food products which are most frequently contaminated with salmonella, and thus are a source for the occurrence of infection. The same agency claims that in Bosnia and Herzegovina during 2015, a total of 881 cases of illness were registered, from which the source/infectious pathway was food. Infections caused by Salmonella species with a share of 398 cases, in this way contributed to the total number of registered cases of disease [19].

\section{CONCLUSIONS:}

Salmonella enteritidis group D was the most frequently isolated serotype. This salmonella was isolated in
$94.2 \%$ of patients. Isolated salmonella serotypes showed the largest resistance to Ampicillin. To this antibiotic, resistance was established in $91.3 \%$ of patients. In controlling occurrence and distribution of resistance, a multidisciplinary approach is important, which includes various experts (epidemiological, microbiological, pharmaceutical, and so on). Finally, it is necessary once again to put emphasis on prevention and the importance of keeping and implementing the measures prescribed by prevention guidelines in preventing the onset of the infection itself. Removing the source of infection, halting the paths of the spread of disease, and active immunization are mechanisms in the prevention of salmonellosis.

\section{REFERENCES:}

1. Fàbrega A, Vila J. Salmonella enterica serovar Typhimurium skills to succeed in the host: virulence and regulation. Clin Microbiol Rev. 2013 Apr; 26(2):308-41. [PubMed] [Crossref]

2. Bešlagiæ $\mathrm{E}$, Hamzic $\mathrm{S}$, Mahmutovic-Vranic S, Aljicevic M, Rebic V. [Salmonella. Medical microbiology]. Faculty of Medicine, University of Sarajevo. 2010. 234-40. [in Bosnian]

3. Genus Salmonella. Food technology. 2017 March 26. [Internet]

4. Kauffmann-White-Schema. 2017 March 25. [Internet]

5. How to protect yourself from Salmonella. 2017 March 25. [Internet] [in Croatian]

6. Krkiæ Dautoviæ S. [Intestinal infectious diseases. Infectious diseases]. Faculty of Medicine, University of Sarajevo. 2011. 114-22. [in Bosnian]

7. Non-typhoid salmonellosis. 2017 March 26. Croatian. [Internet]

8. Scallan E, Hoekstra RM, Angulo FJ, Tauxe RV, Widdowson MA, Roy SL, et al. Foodborne illness acquired in the United States-major pathogens. Emerg Infect Dis. 2011 Jan;17(1):7-15. [PubMed] [Crossref]
9. European Food Safety Authority, European Centre for Disease Prevention and Control. The European Union summary report on antimicrobial resistance in zoonotic and indicator bacteria from humans, animals and food in 2014. EFSA Journal. 2016 Feb;14(2):4380. pp.207. [Crossref]

10. Tyfus. 2017 March 26. Croatian. [Internet]

11. Magill AJ. Typhoid and Paratyphoid fever. Hunter's tropical medicine and emerging infectious diseases (9th ed.). London: Saunders/Elsevier; 2013. 568-76.

12. Crump JA, Medalla FM, Joyce KW, Krueger AL, Hoekstra RM, Whichard JM, et al. Antimicrobial resistance among invasive nontyphoidal Salmonella enterica isolates in the United States: National Antimicrobial Resistance Monitoring System, 1996 to 2007. Antimicrob Agents Chemother. 2011 Mar;55(3):1148-54. [PubMed] [Crossref]

13. Salmonella. Prevention. Centres for Disease Control and Prevention. 2017 March 31. [Internet]

14. Salmonellosis. 2017 April 1. [in

\section{Croatian] [Internet]}

15. Tambiæ Andraševiæ A, Tambiæ T. [Sensitivity and resistance of bacteria to antibiotics in Croatia in 2015.] Academy of Medical Sciences of Croatia. 2016; 58-60. [in Croatian]

16. Tambiæ Andraševiæ A, Tambiæ T. [Sensitivity and resistance of bacteria to antibiotics in Croatia in 2014.] Academy of Medical Sciences of Croatia. 2015; 56-8. [in Croatian]

17. Tambiæ Andraševiæ A, Tambiæ T. [Sensitivity and resistance of bacteria to antibiotics in Croatia in 2013.] Academy of Medical Sciences of Croatia. 2013; 54-6. [in Croatian]

18. European Food Safety Authority, European Centre for Disease Prevention and Control. The European Union summary report on antimicrobial resistance in zoonotic and indicator bacteria from humans, animals and food in 2015. EFSA Journal. 2017 Feb;15(2):4694. pp.212. [Crossref]

19. Food Safety Agency of Bosnia and Herzegovina. Report on the state of food safety in Bosnia and Herzegovina for 2015. FSA of BiH. 2016; 1-44. [in Bosnian]

Please cite this article as: Aljicevic M, Cikotic A, Bektas S, Mahmutovic Vranic S, Rebic V, Abduzaimovic A, Cemerlic A. Antibiotic susceptibility/resistance among Salmonella species isolated in non-hospitalised patients in the canton ofOF Sarajevo. J of IMAB. 2019 Apr-Jun;25(2):2532-2536. DOI: https://doi.org/10.5272/jimab.2019252.2532

\author{
Address for correspondence: \\ Mufida Aljicevic \\ Department of Microbiology, Faculty of Medicine, University of Sarajevo, \\ Bosnia and Herzegovina \\ E-mail: mufida.aljicevic@mf.unsa.ba
}

